\title{
Hugues Puel, Les souverainetés. Pouvoirs religieux.
} Pouvoirs séculiers

Paris, Les Éditions du Cerf, coll. « Recherches morales », 2012, 286 p.

\section{Cornelius Crowley}

\section{(2) OpenEdition}

\section{Journals}

Édition électronique

URL : http://journals.openedition.org/assr/26545

DOI : $10.4000 /$ assr. 26545

ISSN : $1777-5825$

Éditeur

Éditions de l'EHESS

Édition imprimée

Date de publication : 31 décembre 2014

Pagination : 282

ISBN : 978-2-7132-2467-6

ISSN : 0335-5985

\section{Référence électronique}

Cornelius Crowley, «Hugues Puel, Les souverainetés. Pouvoirs religieux. Pouvoirs séculiers », Archives de sciences sociales des religions [En ligne], 168 | 2014, mis en ligne le 19 mai 2015, consulté le 22 septembre 2020. URL : http://journals.openedition.org/assr/26545; DOI : https://doi.org/10.4000/ assr. 26545

Ce document a été généré automatiquement le 22 septembre 2020.

(c) Archives de sciences sociales des religions 


\section{Hugues Puel, Les souverainetés. Pouvoirs religieux. Pouvoirs séculiers}

Paris, Les Éditions du Cerf, coll. « Recherches morales », 2012, 286 p.

Cornelius Crowley

\section{RÉFÉRENCE}

Hugues Puel, Les souverainetés. Pouvoirs religieux. Pouvoirs séculiers, Paris, Les Éditions du Cerf, coll. « Recherches morales », 2012, 286 p. 
$1 \quad$ Le livre ne propose pas un nouveau traité de la souveraineté. Il est d'ailleurs question de souverainetés, au pluriel, des articulations entre des pouvoirs pluriels, religieux et séculiers. Pour autant, on ne dira pas que le livre d'Hugues Puel, auteur d'une abondante œuvre, depuis Violences et société (1969) à Éthique pour l'économie (2010), n'est pas animé d'une puissante interrogation théologique quant à la possibilité de la souveraineté ou quant aux leurres inhérents à sa "prétention » (p. 260). Les différents titres publiés par l'auteur depuis plus de quarante ans, de même que le schéma d'articulation entre catégories qui structure le présent livre, où il est question d'" un pouvoir spirituel aux prises avec des souverainetés en concurrence ", titre de la première partie (p. 21-81), dénotent la volonté d'exposer

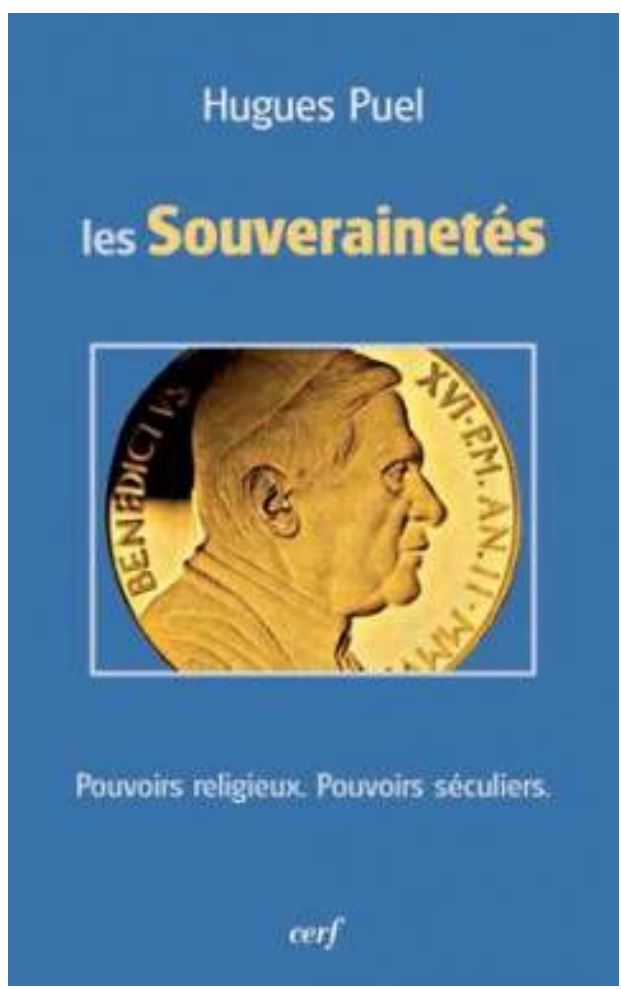
une unité notionnelle qui se prétend souverain à son autre, à son dehors, que selon la compréhension habituelle on voudrait souverainement réduire. Est souverain le pouvoir qui règne sans partage, pouvoir dont l'accomplissement est pressenti par St. Paul, 1 Cor $15: 25$ : «Car il faut qu'il règne jusqu'à ce qu'il ait placé tous ses ennemis sous ses pieds ». En attendant, les pouvoirs de ce monde composent en des articulations instables, selon des dynamiques de devenir souverain qui ont pour concomitant l'exercice de la domination comme réduction. Ce livre, qui fait l'inventaire des figures de la souveraineté revendiquée par un pouvoir d'Église ou par un pouvoir civil, pointe l'achoppement de cette revendication sur l'ouverture et l'inachèvement qui sont les modalités constitutives de la « mondanéité du monde » (p. 260).

2 La trame du livre est faite d'une articulation entre plusieurs temporalités. Celles-ci sont de longueur variable, mais toujours ancrées dans l'expérience indécise de l'histoire vécue. D'abord il y a l'empan d'une histoire contemporaine, qui va de la préparation du Concile de Vatican II jusqu'à un retour à l'ordre dogmatique qui s'effectue au cours du pontificat de Jean-Paul II (p.113-122), suivi des révélations concernant des scandales financiers et les opacités de la gouvernance vaticane. Cette première temporalité épouse le parcours de l'engagement religieux de l'auteur. Publié peu de temps avant l'élection du pape François, le livre permet de comprendre les espoirs que suscite ce nouveau pontificat. D'une plus longue durée, mais toujours inscrite en aval de la révolution française et l'avènement occidental d'une modernité libérale, se situe une temporalité qui s'étend depuis l'éviction de la papauté de l'ordre des États souverains, avec la profonde mutation que représente pour le souverain pontife le « dépouillement de ses souverainetés ", suscitant en réaction un travail d'ajustement, à la fois tactique, doctrinale, théologique. Pour Hughes Puel, cet ajustement de l'institution dépouillée se réalisera à travers des gestes dogmatiques- doctrine de l'infaillibilité papale, fermeture doctrinale antimoderniste - mais également à travers l'élaboration de ce qu'il qualifie 
de « doctrine religieuse qui sert généralement de référence aux catholiques sociaux, la doctrine sociale de l'Église (DSE)» (p. 7). Hugues Puel se penche aussi sur la temporalité des origines, qui va de l'Église primitive jusqu'à l'achèvement institutionnel de celle-ci, quand «Le pêcheur de Galilée est devenu le souverain pontife avec sa tiare aux trois couronnes représentant le cumul des souverainetés spirituelle, temporelle et romaine » (p. 260). Cet aboutissement, dont l'emblème est le baptême de Constantin « sur son lit de mort » (p. 34), signe l'avènement « du couple théologico-politique qui va marquer en profondeur l'histoire de l'Église » (p. 34).

3 Cette temporalité de l'accomplissement théologico-politique, qui va de l'empereur Constantin au « dépouillement » des années 1860, quand « le pape Pie IX s'est vu privé de ses États» (p. 193), représente la plus longue des envergures temporelles envisagées ici. L'accomplissement théologico-politique - qui, au lieu d'un pluriel antagoniste, offre le paradigme d'une résolution consommée - pose les termes de la méditation sur les souverainetés qui est conduite par Hughes Puel dans ce livre : à la fois en amont de l'institutionnalisation du pontifex romain, puis en son aval, depuis ce "dépouillement " donc, et à travers une époque encore empreinte du sceau de cette "prétention » à la résolution théologico-politique. Car l'installation théologico-politique de cette longue époque commencée avec Constantin aura fourni une assise, à la fois dans ce monde et en surplomb de ce monde, à l'exercice de la souveraineté. Hughes Puel conclut son livre en déclarant: «Il n'était donc pas inutile de traquer les restes de cette prétention, y compris dans le discours social de l'Église en distinguant, plus qu'il ne l'est fait couramment, la prédication de l'Évangile social et l'idéologie du pouvoir romain » (p. 260).

4 Or ce livre, qui ne revendique nullement l'objectivité magistrale d'un traité, enchâsse les différentes temporalités dans une dimension autrement plus vaste et autrement ouverte. En partant de cette première temporalité «vécue " - des espoirs surgis et déçus du moment conciliaire - l'intention de l'auteur est de libérer la compréhension de la doctrine sociale de l'Église de tout reste d'inféodation «théologico-politique ». Il s'agit de ressourcer cette doctrine dans les attentes apostoliques de la première Église, de l'épurer de toute velléité d'installation dans le champ des souverainetés temporelles, pour ainsi l'ouvrir sur la pleine amplitude eschatologique. Tout l'intérêt du livre d'Hugues Puel tient à l'enchâssement d'un parcours personnel et du destin de l'Église, depuis son accomplissement théologico-politique jusqu'aux séquelles de son "dépouillement", dans une approche eschatologique comportant une ouverture audelà d'une compréhension de la souveraineté comme exercice du pouvoir sans reste, mais sans pour autant se complaire dans la fuite hors de ce monde. Ce que Puel veut sauvegarder d'une doctrine sociale de l'Église, c'est l'immersion dans les incertitudes d'une histoire en devenir. Ainsi il ne suffit pas de prononcer le mot eschatologie, de l'invoquer comme une valeur-fétiche, pour lever la chape surplombante des certitudes théologico-politiques. À lire Hugues Puel, l'invocation de la modalité eschatologique du temps obligerait le sujet collectif de l'Église à accepter que son message « est celui de l'avènement dans le monde de la cité de Dieu, une cité eschatologique, c'est-à-dire cachée dans la mondanéité du monde. Elle rassemble non seulement les saints ayant déjà traversé l'histoire terrestre, mais aussi les saints encore en pèlerinage sur terre. Ceux-ci sont également invisibles aux yeux des hommes, tant que le bon grain du Royaume n'a pas été séparé du mauvais » (p. 260). 
5 C'est là, il me semble, le passage le plus engagé de ce livre, le plus aventureux sur les chemins d'une théologie de la révélation. Cette révélation d'une "cité eschatologique [...] cachée dans la mondanéité du monde ", parce qu'elle ne promet que la révélation d'une vérité cachée, destinée à demeurer en tant que chose cachée, inséparable de «la mondanéité du monde ", permet d'éviter de faire de la modalité eschatologique une instance de plus de la prétention récurrente au statut théologico-politique. On peut supposer que la conclusion du livre d'Hugues Puel situe le moment de décision, d'un jugement éminemment souverain, au-delà de la «mondanéité » et de la temporalité communément vécue. En effet, c'est à la condition d'un report de ce moment décisif permettant de discerner le «bon grain » qui, en attendant, «n'a pas été séparé du mauvais ", que les abîmes de la "prétention" théologico-politiques peuvent être évitées. Et c'est en s'attachant au travail interminable de discernement de ce qui est en cours dans "la mondanéité du monde " qu'un monde habitable reste pensable, de l'ordre de ce qui, collectivement ou socialement - pour revenir à la DES - relève d'une théologie de la libération. Car le lecteur notera l'invocation stratégique d'une théologie de la libération, objet d'un chapitre (p.123-136), et qualifiée par l'auteur, à la suite de Jean-Baptiste Metz, de «théologie qui prendrait au sérieux la mondanéité du monde » (p. 258). Cela permet à ce livre d'indiquer une position non souveraine, à l'opposé de la compréhension dogmatique d'une DES qui aurait pour vocation de proposer un contreordre social romanisé. Cette position non-souveraine, aux prises avec la "mondanéité du monde ", se distingue également des chimères d'un primitivisme ou d'un eschatologisme qui romprait avec le monde ou qui romprait le monde, qui ferait de l'axiome pereat mundus l'alpha et l'oméga d'une souveraine maîtrise, réductionniste, de la temporalité ouverte de la mondanéité. 